\title{
The Friedman Rule and the Zero Lower Bound
}

\author{
Sebastien Buttet $^{1} \&$ Udayan Roy ${ }^{2}$ \\ ${ }^{1}$ Department of Business and Economics, School of Business and Information Systems, York College, United \\ States \\ ${ }^{2}$ Department of Economics, College of Liberal Arts and Sciences, LIU Post, United States \\ Correspondence: Sebastien Buttet, Department of Business and Economics, School of Business and Information \\ Systems, York College, 94-20 Guy R. Brewer Blvd, Jamaica, NY 11451, United States. Tel: 1-718-262-2502. \\ E-mail: sbuttet@york.cuny.edu
}

Received: September 2, 2013

Accepted: October 5, $2013 \quad$ Online Published: October 26, 2013

doi:10.5539/ijef.v5n11p22

URL: http://dx.doi.org/10.5539/ijef.v5n11p22

\begin{abstract}
We explain why central banks rarely implement the Friedman rule by studying the properties of a simple New Keynesian dynamic macroeconomic model that is generalized to incorporate the zero lower bound on nominal interest rates. We show that two long-run equilibria exist, one stable and the other unstable, and we characterize the conditions under which the economy plunges into a deflation-induced depression following a contractionary demand shock. As long as the sum of the inflation rate and the natural real interest rate stays positive, the economy converges back to the long-run stable equilibrium, even when the zero lower bound is initially binding. On the other hand, a deflationary spiral starts when the sum of the inflation rate and the natural rate of interest becomes negative. The Friedman rule, which calls for a small dose of anticipated deflation, takes the sum of the inflation rate and the natural real interest rate uncomfortably close to zero and thereby raises the probability of the economy plunging into a depression. Our theoretical results also shed light onto the different correlation values between inflation and economic growth in the data.
\end{abstract}

Keywords: Friedman rule, zero lower bound, inflation, growth

\section{Introduction}

In his classic essay on the quantity of money, Friedman (1969) proposed a simple rule to set nominal interest rates in the long-run. In order for consumption, savings, and labor supply decisions of those who hold money not to be distorted, the (private) opportunity cost of holding money should equal the social cost of creating additional money. Since in a fiat monetary system central banks can print money at virtually no cost, the Friedman rule calls for setting nominal interest rates to zero in the long-run.

A large body of academic research has shown that the Friedman rule holds in a variety of monetary economies with monopolistic competition (Ireland, 1996), distorting taxes (Chari et al., 1996) or search frictions (Lagos, 2010). In addition, Cole \& Kocherlakota (1998) characterize the monetary policies that will implement zero rates in the one sector neoclassical growth model. They show that the only restriction these policies must satisfy is that asymptotically money shrinks at a rate no greater than the rate of discount which implies a small amount of deflation in goods prices.

While much ink has been spilt about the Friedman rule in academic circles, there is little evidence that central banks around the world have or are ready to adopt a long-run target of zero nominal interest rates. In this paper, we explain why central banks rarely implement the Friedman rule by revisiting the properties of a simple New Keynesian dynamic macroeconomic model that is generalized to incorporate the zero lower bound on nominal interest rates.

Reduced-form New Keynesian models of short term economic fluctuations usually do not incorporate any restrictions on nominal interest rates and are built around three equations: an IS curve (the output gap depends on the real interest rate), a Phillips curve (inflation depends on the output gap and last period's expectation of this period's inflation rate), and a Taylor rule with a zero lower bound constraint. Without the zero lower bound on nominal interest rates, the cyclical and long-run properties of New Keynesian models are well known. In the short-run, output and real interest rates are counter-cyclical and, in the absence of shocks, all variables converge toward a unique stable equilibrium where the economy is operating at full capacity and inflation is equal to the 
central bank's inflation target.

The introduction of the zero lower bound changes the model dynamics in the short and long-run. Our economy has now two long-run equilibria: (i) the stable one where nominal interest rates are positive and inflation is equal to the central bank's target and (ii) a new equilibrium with zero nominal interest rates that can lead to a deflationary spiral.

Given the multiplicity of equilibria, several questions about short-term dynamics arise. For a given set of parameter values and initial conditions, to which of the two equilibria does inflation and output converge? Are there equilibrium paths where deflation does not lead to depression? And ultimately, why do central banks rarely implement the Friedman rule?

We find that answers to these questions depend on the sign of a simple expression, the sum of the inflation rate and the natural rate of interest. We show that, as long as the sum of the inflation rate and the natural real interest rate stays positive, the economy converges back to the long-run stable equilibrium, even when the zero lower bound is initially binding. On the other hand, a deflationary spiral starts when the sum of the inflation rate and the natural rate of interest becomes negative. The Friedman rule, which calls for a small dose of anticipated deflation, takes the sum of the inflation rate and the natural real interest rate uncomfortably close to zero and thereby raises the probability of the economy plunging into a depression. We believe that the threat of a policy-induced deflationary spiral is a key factor accounting for policymakers' reluctance to adopt any policy, including the Friedman rule, that may cause deflation.

Our theoretical results also shed light onto the different values for the correlation between inflation and economic growth in the data. There is a tight link between deflation and depression during the Great Depression years and many believe that deflation contributed to the severe output losses in the U.S. and other countries between 1929 and 1932 (Bernanke \& Carey, 1996; Eichengreen \& Sachs, 1985). Outside of the Great Depression years, however, the empirical link between deflation and depression is much weaker (Atkeson \& Kehoe, 2004; Benhabib \& Spiegel, 2009). Our model predictions that (i) mild deflation does not lead to a depression and (ii) deflation and depression are closely linked when the economy is hit by a large demand shock help reconcile and explain the seemingly different patterns for inflation and growth in the data.

Note that our modeling choice of using a system of reduced-form equations differs from the recent macroeconomic literature in two important ways. First, agents' choices are not maximizing a well-defined utility (objective) function, implying that the structural equations of the model, in particular the IS and the Philips curves, are not grounded in microeconomic theory. In the New Keynesian models, the IS curve has consumption (or output) growth depending on the interest rate while the Phillips curve states that inflation is a function of the real marginal cost (or output) and the expected future inflation rate. Second, we assume adaptive expectations in price setting instead of allowing prices to be set in a forward-looking manner. Our main point however, that implementing the Friedman rule is not recommended when the economy is in a liquidity trap because of the possibility of deflation-induced depression, remains valid as long as inflation and output are positively correlated when the zero lower bound is binding (see Krugman (1998) for a fully specified model with micro-foundations where a deflationary spiral can occur).

The remainder of the paper is organized as follows. In Sections 2 and 3, we introduce our model and characterize its long-run equilibria. We discuss the stability of these equilibria in Section 4. We reinterpret empirical findings in light of our theoretical results in Section 5. Finally, we offer concluding remarks in Section 6.

\section{The Model}

We extend a simple New Keynesian model of the business cycle by explicitly incorporating a non-negativity constraint on nominal interest rates. The version of our model without the zero lower bound has replaced the IS-LM model as the mainstay of short-run analysis in macroeconomics textbooks and is variously referred to as the dynamic AD-AS (or DAD-DAS) model in Mankiw (2010), the AS/AD model in Jones (2011), and the 3-equation (IS-PC-MR) model in Carlin and Soskice (2006), where PC refers to the Phillips Curve and MR refers to the central bank's Monetary Policy Rule.

Equilibrium in the market for goods and services is given by

$$
Y_{t}=\overline{\mathrm{Y}}_{t}-\alpha(r-\mathrm{Q})+\varepsilon_{t}
$$

where $\overline{\mathrm{Y}}_{t}$ denotes the natural or full-employment level of output, $r_{t}$ is the real interest rate, $\varrho$ is the natural real 
interest rate of interest, $\alpha$ is a positive parameter representing the responsiveness of aggregate expenditure to the real interest rate, and $\varepsilon_{t}$ represents both demand shocks (say, from changes in private-sector optimism or 'animal spirits') and the government's fiscal policy stance.

This equation is essentially the well-known IS Curve. The key feature of (1) is the negative relationship between the real interest rate $r_{t}$ and output $Y_{t}$. When the real interest rate increases, borrowing becomes more expensive and savings yields a higher reward. As a result, firms engage in fewer investment projects and consumers save more and spend less. These effects reduce the demand for goods and services.

Note that the economy operates at full capacity $\left(Y_{t}=\overline{\mathrm{Y}}\right)$ when there are no demand shocks $\left(\varepsilon_{t}=0\right)$ and when the real interest rate is equal to the natural real interest rate $\left(r_{t}=\mathrm{Q}\right)$.

The ex-ante real interest rate in period $t$ is determined by the Fisher equation and is equal to the nominal interest rate $i_{t}$ minus the inflation expected in the next period:

$$
r_{t}=i-E_{t} \pi_{t+1}
$$

Inflation in the current period, $\pi_{t}$, is determined by a conventional Phillips curve augmented to include the role of expected inflation, $E_{t-1} \pi_{t}$, and exogenous supply shocks, $v_{t}$ :

$$
\pi_{t}=E_{t-1} \pi_{t}+\varphi\left(Y_{t}-\overline{\mathrm{Y}}{ }_{t}\right)+v_{t}
$$

with $\varphi$ is a positive parameter.

The random variable $v_{t}$ captures all other influences on inflation other than inflation expectations (which are captured in the term $E_{t-1} \pi_{t}$ ) and short-run economic conditions (which are captured in the term $\varphi\left(Y_{t}-\bar{Y}_{t}\right)$ ). For example, an increase in oil prices would mean a positive value for $v_{t}$ since higher input prices might force firms to raise the price of their products.

Inflation expectations play a key role in both the Fisher equation (2) and the Phillips curve (3). To keep the model tractable analytically and because the role of expectations was analyzed in great detail in Eggertson and Woodford $(2003,2004)$, we assume that inflation in the current period is the best forecast for inflation in the next period. That is, agents have adaptive expectations with:

$$
E_{t} \pi_{t+1}=\pi_{t}
$$

Finally, we complete the description of the model with a rule for monetary policy. Dynamic New Keynesian models assume that the central bank sets a target for the nominal interest rate, $i_{t}$, based on the inflation gap and the output gap according to the Taylor rule (Taylor, 1993). Specifically, it is assumed that $i_{t}=\pi_{t}+\mathrm{Q}^{+} \Theta_{\pi t}\left(\pi_{t}-\pi_{t}^{*}\right)+\Theta_{Y t}\left(Y_{t}-\overline{\mathrm{Y}}\right)$, where the central bank's policy parameters $\Theta_{\pi t}$ and $\Theta_{Y t}$ are non-negative. We, however, wish to explicitly incorporate the fact that nominal interest rates need to be non-negative. Therefore, our monetary policy rule is:

$$
i_{t}=\max \left\{0, \pi+\varrho_{t}^{+}+\Theta_{\pi t}\left(\pi_{t}-\pi_{t}^{*}\right)+\Theta_{Y t}\left(Y_{t}^{-}-\bar{Y} t\right)\right\} .
$$


Although the central bank sets a target for $i$, its true influence on the economy works through the real interest rate, $r_{t}$. When inflation in period $t$ is equal to the central bank's target $\left(\pi_{t}=\pi_{t}^{*}\right)$ and output is at its natural level $\left(Y_{t}=\overline{\mathrm{Y}} t\right)$, the last two terms in equation (5) are equal to zero, implying that the real rate is equal to the natural rate of interest $\left(r_{t}=\mathrm{Q}\right)$. As inflation rises above the central bank's target $\left(\pi_{t}>\pi_{t}^{*}\right)$ or output rises above its natural level $\left(Y_{t}>\overline{\mathrm{Y}} t\right)$, the Taylor rule ensures that the real rate rises to bring down inflation and/or output. Conversely, if inflation falls below the central bank's target $\left(\pi_{t}<\pi_{t}^{*}\right)$ or output falls below its natural level $\left(Y_{t}<\overline{\mathrm{Y}}\right)$, the real interest falls to provide a stimulus to the economy.

\section{Long-Run Equilibria}

For given values of the model's period- $t$ parameters $\left(\alpha, \varrho, \varphi, \Theta_{\pi t}, \Theta_{Y t}, \pi_{t}^{*}\right.$, and $\left.\bar{Y}_{t}\right)$, its period- $t$ shocks $\left(\varepsilon_{t}\right.$ and $\left.v_{t}\right)$, and the pre-determined inflation rate $\left(\pi_{t-1}\right)$ for period $t-1$, one can use the the model's five equations to solve for its five period- $t$ endogenous variables $\left(Y_{t}, r_{t}, i_{t}, E_{t-1} \pi_{t}\right.$, and $\left.\pi_{t}\right)$. Once $\pi_{t}$ is determined, the process can be repeated for period $t+1$, and so on and on.

To study the model's dynamic properties algebraically-as opposed to numerically-we will simplify the model by assuming a constant target inflation rate: that is, $\pi_{t}^{*}=\pi^{*}$ for all $t$.

Definition 1. An equilibrium is a sequence for output, inflation, nominal and real interest rates $\left\{Y_{t} \pi_{t} E_{t-1} \pi_{t} i_{t}, r_{t}\right\}$ such that the model's equations (1)-(5) are satisfied at all time $t$.

Definition 2. A long-run equilibrium is any equilibrium sequence such that, in the absence of shocks $\left(\varepsilon_{t}=v_{t}=0\right.$ for all $t$ ), the inflation rate $\pi_{t}$ is constant.

It is then straightforward to identify the two long-run equilibria of the model. First, one can check that if $\pi_{t-1}=\pi^{*}$ and there are no shocks, then $\pi_{t+s}=\pi^{*}$ for all subsequent periods. We will refer to this long-run equilibrium as the orthodox equilibrium. Real output is equal to potential output in all periods, $Y_{t+S}=\overline{\mathrm{Y}}_{t+s}$; the real interest rates is equal to the natural rate of interest, $r_{t+s}=\mathrm{Q}$, and nominal interest rates is constant and equal to $i_{t+S}=\mathrm{Q}^{+\pi} \pi^{*}$.

Second, one can check that, if $\pi_{t-1}=-\mathrm{Q}$ and there are no shocks, then $\pi_{t+S}=-\mathrm{Q}$ is also an equilibrium. We refer 
to this long-run equilibrium as the deflationary equilibrium. Real output is equal to potential output, $Y_{t+s}=\overline{\mathrm{Y}}_{t+s^{\prime}}$,

real interest rate is equal to the natural rate of interest, $r_{t+s}=\mathrm{Q}$, and nominal interest rates are zero forever, $i_{t+S}=0$.

\section{Stability of Equilibrium}

The issue of stability inevitably arises: How does the economy behave for arbitrary values of $\pi_{t-1}$ ? Will it converge to one of the two long-run equilibria? If so, which one?

To analyze the stability properties of the DAD-DAS model, we need to solve for the model's endogenous variables for the case in which the zero lower bound on the nominal interest is not binding and again for the case in which the zero lower bound is binding.

\subsection{Zero Lower Bound is Non-Binding}

When the zero lower bound is not binding, the monetary policy rule (5) becomes

$$
i=\pi_{t}+\mathrm{Q}^{+} \Theta_{\pi t}\left(\pi_{t}-\pi_{t}^{*}\right)+\Theta_{Y t}(Y-\overline{\mathrm{Y}}) .
$$

Therefore, the economy is described by equations (1)-(4) and (6). Using these equations, it is straightforward, if tedious, to derive expressions for the model's endogenous variables in terms of the parameters of the model and the pre-determined inflation rate of the previous period. Specifically, it can be shown that equilibrium output is

$$
Y_{t}=\bar{Y} t+\frac{\alpha \Theta_{t}\left(\pi_{t}^{*}-\pi_{t-1}-v_{t}\right)+\varepsilon_{t}}{1+\alpha\left(\Theta_{\pi t} t^{\varphi+\Theta} Y t\right.}
$$

equilibrium inflation is

$$
\pi=\frac{\left(1+\alpha \Theta_{Y t}\right) \cdot\left(\pi_{t-1}+v_{t}\right)+\alpha \Theta_{t} \varphi t_{t} \pi_{t}^{*}+\varphi \varepsilon_{t}}{1+\alpha\left(\Theta_{\pi t}{ }^{\varphi+\Theta}\right)},
$$

and the equilibrium nominal interest rate is

$$
\begin{aligned}
& i_{t}=\rho+\frac{1}{1+\alpha\left(\Theta_{\pi t} \varphi+\Theta_{Y t}\right)} \times \\
& {\left[\left(1+\Theta_{\pi} \varphi+\alpha \Theta_{Y t}\right)\left(\pi_{t-1}+v_{t}\right)-(1-\alpha \varphi) \Theta_{\pi t} \pi_{t}^{*}+\left(\Theta_{Y t}+\left(1+\Theta_{\pi t}\right) \varphi\right) \varepsilon_{t}\right]}
\end{aligned}
$$

As the Fisher equation (2) and adaptive expectations (4) imply $r_{t}=i-\pi_{t}$, the equilibrium real interest rate can be derived from equations (8) and (9) above.

It follows from (7) that, in the usual case where the zero lower bound on the nominal interest rate is not binding, output $\left(Y_{t}\right)$ is directly related to full-employment output $\left(\bar{Y}_{t}\right)$, the demand shock $\left(\varepsilon_{t}\right)$, and the central bank's target inflation $\left(\pi_{t}^{*}\right)$, and inversely related to the previous period's inflation $\left(\pi_{t-1}\right)$, the inflation shock $(v)$, the responsiveness of inflation to output in the Phillips Curve $(\varphi)$, and the responsiveness of the nominal interest rate to output in the monetary policy rule $\left(\Theta_{Y t}\right)$. It follows from $(8)$ that inflation $\left(\pi_{t}\right)$ is directly related to $\pi_{t-1}, v_{t}$, 


$$
\pi_{t}^{*} \text {, and } \varepsilon_{t}
$$

Figure 1 graphs the dynamic mapping from $\pi_{t-1}$ to $\pi_{t}$ for given values of all the parameters in equation (8) and the shocks set at zero $\left(\varepsilon_{t}=v_{t}=0\right)$. It can be checked that this graph-which we will call the inflation mapping curve-must intersect the 45-degree line at $\pi_{t-1}=\pi_{t}^{*}$, because $\pi_{t-1}=\pi_{t}^{*}$ implies $\pi_{t}=\pi_{t-1}=\pi_{t}^{*}$. This represents the orthodox long-run equilibrium.

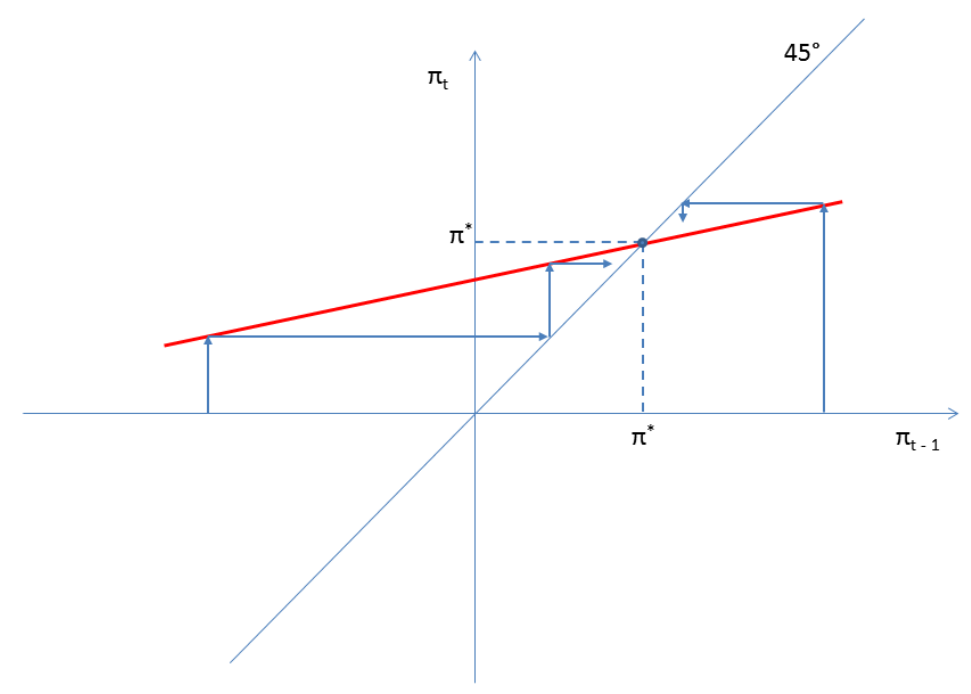

Figure 1. Dynamics without the zero lower bound on the nominal interest rate

The dynamic mapping from $\pi_{t-1}$ to $\pi_{t}$ when there are no shocks $\left(\varepsilon_{t}=v_{t}=0\right)$ and the zero lower bound on the nominal interest rate is non-binding is shown here. For any given value of $\pi_{t-1}$, the inflation mapping curve and the 45-degree line can be used to trace inflation in subsequent periods. The orthodox long-run equilibrium $\left(\pi_{t-1}=\pi^{*}\right)$ can be seen to be stable. (TC "1 Dynamics without the zero lower bound on the nominal interest rate The dynamic mapping from $\pi_{t-1}$ to $\pi_{t}$ when there are no shocks $\left(\varepsilon_{t}=v_{t}=0\right)$ and the zero lower bound on the nominal interest rate is non-binding is shown here. For any given value of $\pi_{t-1}$, the inflation mapping curve and the 45-degree line can be used to trace inflation in subsequent periods. The orthodox long-run equilibrium $\left(\pi_{t-1}=\pi^{*}\right)$ can be seen to be stable.

Note also that the inflation mapping curve must be flatter than the 45 -degree line as its slope is a positive 
fraction: that is:

$$
\partial \pi_{t} / \partial \pi_{t-1}=\left(1+\alpha \Theta_{Y t}\right) /\left(1+\alpha \Theta_{Y t}+\alpha \Theta_{t} \varphi\right) \in(0,1)
$$

As is shown in Figure 1, this feature of the inflation mapping curve when the zero lower bound on the nominal interest rate is not binding and there are no shocks implies that the orthodox long-run equilibrium is stable. (The stability of the deflationary long-run equilibrium will be discussed below.)

To guarantee the intuitive result that a positive demand shock increases output in equation (7), we assume that $1-\alpha \varphi>0$ in this paper. It then follows from (9) that the nominal interest rate, assuming it is not at the zero lower bound, is directly related to $\varrho$ and to all exogenous variables and shocks that are directly related to inflation.

Note that these results prevail only when $i$, as given by (9), is non-negative. It can be checked that (9) implies

$$
i_{t}\left\{\begin{array}{l}
> \\
=
\end{array}\right\} 0 \quad \text { if and only if } \quad \pi_{\mathrm{t}-1}\left\{\begin{array}{l}
> \\
\leq \leq
\end{array} \pi_{\mathrm{t}-1}^{\mathrm{c}},\right.
$$

where

$$
\pi_{\mathrm{t}-1}^{\mathrm{c}} \equiv \frac{(1-\alpha \varphi) \Theta_{\pi \mathrm{t}} \pi_{\mathrm{t}}^{*}-\left(1+\alpha \Theta_{\pi \mathrm{t}}{ }^{\varphi+\alpha \Theta_{\mathrm{Yt}}}\right)-\left(\Theta_{\pi \mathrm{t}}{ }^{\varphi+\Theta_{\mathrm{Yt}}}+\varphi\right) \varepsilon_{\mathrm{t}}}{1+\Theta_{\pi \mathrm{t}}+\alpha \Theta_{\mathrm{Yt}}}-v_{\mathrm{t}}
$$

is the critical value for the previous period's inflation rate such that the equilibrium nominal interest rate is given by equation (9) when $\pi_{t-1} \geq \pi_{t-1}^{c}$, and is zero when $\pi_{t-1} \leq \pi_{t-1}^{c}$.

The line segment $B C$ in Figure 2 graphs the dynamic mapping from $\pi_{t-1}$ to $\pi_{t}$ in equation (8) for $\pi_{t-1} \geq \pi_{t-1}^{c}$ when there are no shocks and the central bank has a constant target inflation $\left(\pi_{t}^{*}=\pi^{*}\right)$.

A quick comparison of Figures 1 and 2 emphasizes the fact that the introduction of the zero lower bound on the nominal interest rate sharply restricts the domain over which equation (8) is applicable. Note, as before, that the coefficient of $\pi_{t-1}$ on the right hand side of equation (8) is a positive fraction, which explains why $B C$ is drawn flatter than the 45-degree line. At $\pi_{t-1}=\pi^{*}, B C$ intersects the 45-degree line, indicating the orthodox long-run equilibrium of section. It can be checked from (11) that, in the absence of shocks, $\pi_{t-1}^{c}$ is a convex combination of $\pi^{*}$ and $-\mathrm{Q}$. Our assumption that $\pi^{*}+\mathrm{Q}>0$ then implies $\pi^{*}>\pi_{t-1}^{c}>-\varrho$, as shown in Figure 2. 


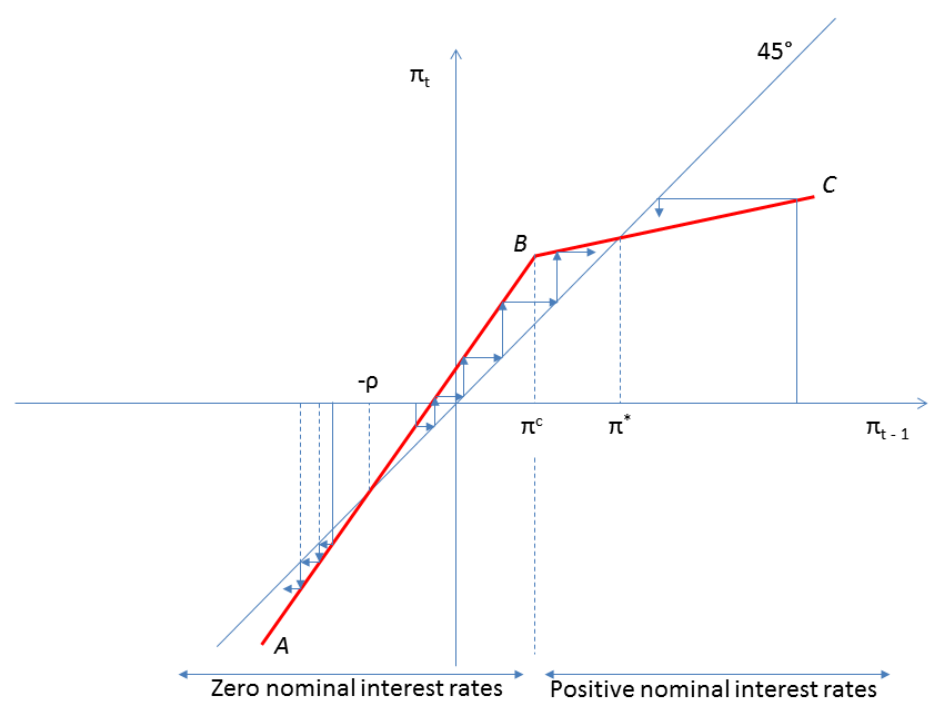

Figure 2. Stability $A B C$ represents the dynamic mapping from $\pi_{t-1}$ to $\pi_{t}$ when there are no shocks $\left(\varepsilon_{t}=v_{t}=0\right)$

$A B$ represents an economy in which the zero lower bound on the nominal interest rate is binding, and $B C$ represents the same economy when the zero lower bound on the nominal interest rate is non-binding. For any given value of $\pi_{t-1}, A B C$ and the 45 -degree line can be used to trace inflation in subsequent periods. The orthodox long-run equilibrium $\left(\pi_{t-1}=\pi^{*}\right)$ can be seen to be stable, whereas the deflationary long-run equilibrium $\left(\pi_{t-1}=-\varrho\right)$ can be seen to be unstable. (TC "2 Stability $A B C$ represents the dynamic mapping from $\pi_{t-1}$ to $\pi_{t}$ when there are no shocks $\left(\varepsilon_{t}=v_{t}=0\right) . A B$ represents an economy in which the zero lower bound on the nominal interest rate is binding, and $B C$ represents the same economy when the zero lower bound on the nominal interest rate is non-binding. For any given value of $\pi_{t-1}, A B C$ and the 45 -degree line can be used to trace inflation in subsequent periods. The orthodox long-run equilibrium $\left(\pi_{t-1}=\pi^{*}\right)$ can be seen to be stable, whereas the deflationary long-run equilibrium $\left(\pi_{t-1}=-\varrho\right)$ can be seen to be unstable.

In the absence of shocks $\left(\varepsilon_{t}=v=0\right)$, equation (8) reduces to

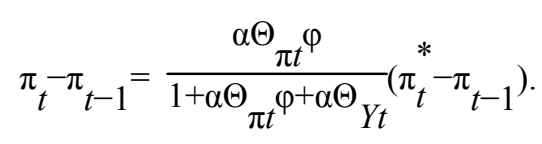

Note that whenever the central bank's target inflation rate, $\pi_{t}^{*}$, exceeds (respectively, is less than) the previous period's inflation, $\pi_{t-1}$, the current period's inflation rises (respectively, falls), while still remaining less 
(respectively, greater) than the target inflation. In other words, if there are no shocks and the target inflation is constant and $\pi_{t-1} \geq \pi_{t-1}^{c}$, the inflation rate converges over time to the central bank's target inflation rate.

Under adaptive expectations and in the absence of shocks, the Phillips Curve yields

$$
\varphi \cdot\left(Y_{t}^{-}-\bar{Y}\right)=\pi_{t}-\pi_{t-1}=\frac{\alpha \Theta \pi t^{\varphi}}{1+\alpha \Theta_{\pi t} \varphi^{+\alpha \Theta} Y t}\left(\pi_{t}^{*}-\pi_{t-1}\right) .
$$

The convergence of inflation to target inflation therefore implies the convergence of equilibrium output to the full-employment output. Therefore, according to the Taylor Rule (5 or 6), the nominal interest rate set by the central bank will converge to $i^{*}=\pi^{*}+\varrho>0$. And, by the Fisher equation (2) the real interest rate converges to $\varrho$. We have, therefore, established the following:

Proposition 1. When there are no shocks and $\pi_{t-1} \geq \pi_{t-1}^{c}$, the economy converges to the orthodox long-run equilibrium.

\subsection{Zero Lower Bound Is Binding}

It follows from (10) that, when $\pi_{t-1}<\pi_{t-1}^{c}$, the zero lower bound on the nominal interest rate becomes binding: that is,

$$
i_{t}=0 \text {. }
$$

In this case, recall that the economy is described by equations (1)-(4) and (13). Using these equations, it is straightforward, as before, to derive expressions for the endogenous variables at time $t$ in terms of the parameters of the model and the pre-determined inflation rate of the previous period. Specifically,

$$
\text { equilibrium output is } Y_{t}=\bar{Y}_{t}+\frac{\alpha\left(\pi_{t-1}+v_{t}+\varrho\right)+\varepsilon}{1-\alpha \varphi}
$$

and equilibrium inflation is

$$
\pi_{t}=\frac{1}{1-\alpha \varphi}\left(\pi_{t-1}+v_{t}\right)+\frac{\varphi}{1-\alpha \varphi}\left(\alpha \varrho+\varepsilon_{t}\right)
$$

Note that the coefficient of $\pi_{t-1}$ in (15) exceeds unity. This is why the segment $A B$ in Figure 2, which shows the dynamic link between $\pi_{t-1}$ and $\pi_{t}$ for $\pi_{t-1} \leq \pi_{t-1}^{c}$ when there are no shocks, is steeper than the 45-degree line. Also, it can be checked that equating the right hand sides of equations (8) and (15) yields $\pi_{t-1}=\pi_{t-1}^{c}$, thereby confirming the continuity of the mapping of $\pi_{t-1}$ to $\pi_{t}$ at $\pi_{t-1}=\pi_{t-1}^{c}$ in Figure 2 .

The contrast between equation (7), when the zero lower bound is not binding, and equation (14), when the zero lower bound is binding, is striking. It follows from (14) that now $\pi_{t-1}, v_{t}$, and $\varphi$ are directly related to output. Moreover, output is now directly related to the responsiveness of aggregate demand to the real interest rate $(\alpha)$

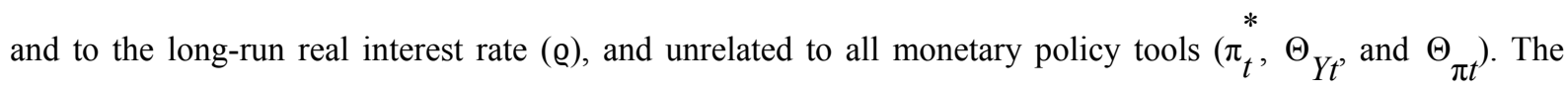


ineffectiveness of monetary policy follows from the fact that the nominal interest rate is now at the zero lower bound and monetary policy is, therefore, unable to influence the nominal interest rate.

It follows from equation (15) that inflation is directly related to $\pi_{t-1}, v_{t}$, $\varphi$, and $\varepsilon_{t}$, as it is in equation (8), which describes inflation when the zero lower is not binding. Now, however, $\alpha$ and $\varrho$ have a direct effect on inflation, and the monetary policy tools have no effect at all (for the reason discussed in the previous paragraph).

Subtracting $\pi_{t-1}$ from both sides of equation (15) yields

$$
\pi_{t}-\pi_{t-1}=\frac{\alpha \varphi}{1-\alpha \varphi} \cdot\left(\pi_{t-1}+\varrho\right)
$$

This confirms our earlier result that when there are no shocks and $\pi_{t-1}=-\varrho$, the economy is in the deflationary long-run equilibrium of section 3.

However, equation (16) also reveals the unstable nature of the deflationary long-run equilibrium. If there are no shocks and if $\pi_{t-1}^{<-\varrho}$, equation (16) implies that inflation keeps falling and, by equation (14) drags output down with it, indefinitely. This is the dreaded deflationary spiral. On the other hand, if there are no shocks and if $\pi_{t-1}^{c}>\pi_{t-1}>-\mathrm{Q}$, inflation and output both keep rising. In short, we have established the following:

Proposition 2. Assume there are no shocks. The deflationary long-run equilibrium is unstable.

As inflation keeps rising when there are no shocks and $\pi_{t-1}^{c}>\pi_{t-1}>-\varrho$, equation (11) implies that inflation will, in finite time, exceed $\pi_{t-1}^{c}$ and that, therefore, the zero lower bound on the nominal interest rate will switch from binding to non-binding.

Therefore, propositions 1 and 2 can be combined to yield the following:

Proposition 3. Assume there are no shocks. If $\pi_{t-1}>-\varrho$, the economy converges to the orthodox long-run equilibrium. If $\pi_{t-1}=-\varrho$, the economy stays in the deflationary long-run equilibrium. If $\pi_{t-1}<-\varrho$, the economy stays in a deflationary spiral.

Proposition 3, which is graphically illustrated in Figure 1, helps explain why central banks rarely implement the Friedman rule as the optimal monetary policy. The Friedman rule, which calls for a small dose of anticipated deflation, makes the sum of inflation and natural rate of interest very close to zero, which makes the economy vulnerable to further shocks and raises the probability that the economy plunges into a depression.

\section{Reinterpretation of Empirical Findings}

In the introduction, we cited the empirical findings of Atkeson and Kehoe (2004), who show that, while the deflation-depression link is strong for the Great Depression years, there is little evidence supporting a statistical relationship between deflation and depression outside of the Great Depression years. Here we briefly summarize their empirical strategy and revisit their findings in light of our results.

The authors use the following simple specification to estimate the relationship between inflation and growth:

$$
\Delta \mathrm{y}_{\text {it }}=\alpha+\beta \pi_{\text {it }}+\varepsilon_{\text {it }}
$$

where $\Delta y_{i t}$ represents average annual growth for country $i$ during five-year period $t, \pi_{i t}$ represents average 
annual inflation for country $i$ during five-year period $t$, and $\varepsilon_{i t}$ represents an i.i.d. normal disturbance term.

The data set consists of historical data on inflation and output growth rates for a panel of 17 different countries. Every data series runs for more than a hundred years and ends in the year 2000. The countries, with the year the data starts given in parenthesis, are: Argentina (1885), Australia (1862), Brazil (1861), Canada (1870), Chile (1908), Denmark (1871), France (1820), Germany (1830), Italy (1867), Japan (1885), the Netherlands (1900), Norway (1865), Portugal (1833), Spain (1849), Sweden (1861), the United Kingdom (1870), and the United States (1820). For all countries except Australia and Denmark, the data up to 1980 are taken from rolnick. The data for Australia and Denmark up to 1980 are taken from backus. The data from 1980 onwards are from the International Financial Statistics of the International Monetary Fund.

For the Great Depression years, the point estimate for the slope $\beta$ is equal to 0.4 , implying that, on average, a one percentage point lower inflation rate is associated with a drop in growth of .4 of a percentage point, say, from 3.40 to 3.00 percent. When the entire time period is considered, however, the value for $\beta$ drops to 0.08 , implying a much weaker link between inflation and growth between 1820 and 2000. Finally, the point estimate of $\beta$ is slightly negative for the years after WWII.

Our theoretical results in Proposition 3 help explain the weak relationship between inflation and output growth outside of the Great Depression years and the tight deflation-depression link during the Great Depression years. When inflation falls below $-\varrho$ and a depression starts, our model clearly predicts a tight link between deflation and depression (see Figure 2). However, the probability of a large demand shock starting a depression is very small. Thus, many equilibrium paths involve a mild case of deflation but no depression, implying a small correlation between inflation and output growth even when the zero lower bound is binding.

Using our model, we calculate the slope of the linear relationship between output growth and inflation, when the zero lower bound is binding and when it is not. That is, we seek to find the parameter $\beta$ such that

$$
\Delta y_{t}=\gamma+\beta \pi_{t}+u_{t}
$$

where $\Delta y_{t}=\frac{Y_{t+1}-Y_{t}}{Y_{t}}$ and $u_{t}$ is a disturbance term. Assuming that the natural output level is constant over time and normalizing it to one, we use equations (7) and (8) to calculate the slope $\beta$ when the zero lower bound is not binding and equations (14) and (15) when it is binding. When the zero lower bound is not binding, we find that the value of $\beta$ is approximately equal to:

$$
\beta^{P O S}=\frac{\alpha^{2} \Theta_{\pi}^{2} \varphi}{\left(1+\alpha \Theta_{Y}\right)\left(1+\alpha\left(\Theta_{\pi} \varphi+\Theta_{Y}\right)\right)}
$$

On the other hand, when the zero lower bound is binding, the slope $\beta$ is approximately equal to:

$$
\beta^{Z L B}=\frac{\alpha^{2} \varphi}{1-\alpha \varphi}
$$

We calculate the slope $\beta^{Z L B}$ and $\beta^{P O S}$ for the following parameter values.

Table 1. Parameter values

\begin{tabular}{ccccccc}
\hline$\overline{\mathrm{Y}}_{t}$ & $\mathrm{~A}$ & $\varrho$ & $\Phi$ & $\Theta_{\pi}$ & $\Theta_{Y}$ & ${ }^{*}$ \\
\hline 100 & 1.0 & 2.0 & 0.25 & 0.5 & 0.5 & 2.0 \\
\hline
\end{tabular}

The first three parameters $\left(\overline{\mathrm{Y}}_{t}, \alpha, \varrho\right) \quad$ appear in the aggregate demand equation (1). A value of 100 for the natural level of output is convenient as fluctuations in $Y_{t}-\bar{Y}_{t}$ can be interpreted as percentage deviation of output from 
its natural level. The parameter $\alpha=1$ implies that a one percentage point increase in the real interest rate reduces the output gap by one percentage point. The natural rate of interest $\varrho$ is equal to 2 percent, in line with historical data. The parameter $\varphi$ appears in the Philips curve in equation (3). The value of 0.25 implies that inflation rises by 0.25 percentage point when output is one percent above its natural level. Finally, the last three parameters affect the Taylor rule in equation (5). The value of one half for the coefficients $\Theta_{\pi}$ and $\Theta_{Y}$ stems directly from Taylor (1993). For each percentage point that inflation rises above the Fed's inflation target, the federal funds rate rises by 0.5 percent. For each percentage point that real GDP rises above the natural level of output, the federal funds rate rises by 0.5 percent. Since $\Theta_{\pi}$ is greater than zero, our equation for monetary policy follow the Taylor principle: whenever inflation increases, the central bank raises the nominal interest rate by an even larger amount. Finally, the inflation target $\pi^{*}$ is equal to 2 percent, reflecting the Fed's concerns of keeping inflation under control, a policy that started thirty years ago under chairman Paul Volcker.

Some interesting remarks are in order. First, when uses the values of $\alpha=1$ and $\varphi=0.25$, we find that $\beta^{Z L B}=0.33$ when the zero lower bound is binding which is very close to the 0.4 estimate in Atkeson and Kehoe (2004) for the Great Depression years, certainly a period of time when the zero lower bound was binding. Second, we find that $\beta^{P O S}=0.025$ if one sets $\Theta_{Y}=\Theta_{\pi}=0.5$ for the Taylor rule as suggested by Taylor (1993). As a result, we have $\beta^{Z L B_{>\beta}} P O S$, which is also in line with the results from the empirical literature. For example, the estimated slope for the Great Depression years, when the zero lower bound is binding, is 0.4 , while for the years excluding the Great Depression but including the wars, the slope is $\beta=0.04$.

\section{Conclusion}

In this paper, we explained why central banks rarely implement the Friedman rule by studying the properties of a simple New Keynesian dynamic macroeconomic model that is generalized to incorporate the zero lower bound on the nominal interest rate. We showed that the model has two long-run equilibria, one stable and the other unstable and demonstrated the existence of a deflationary spiral in which both output and inflation fall without bound. The Friedman rule, which calls for a small dose of anticipated deflation, takes the sum of the inflation rate and the natural real interest rate uncomfortably close to zero and thereby raises the probability of the economy plunging into a depression. We believe that the threat of a policy-induced deflationary spiral is a key factor accounting for policymakers' reluctance to adopt any policy, including the Friedman rule, that may cause deflation.

Our analysis which focuses on long-run stability does not address the short-term limitations that high levels of public debt, which are reflected in a country's credit ratings, place on central bank's ability to raise interest rates now and in the future. Cochrane (2008) argues that risk premiums, which capture default probabilities, are an important factor for understanding monetary policy via the term structure of interest rates. For example, Japan with a stock of debt greater than two times its gross domestic product might not be able to raise interest rates in time, when economic activity and inflation grow at too rapid a rate following recent expansionary policy. Studying monetary policy in a model that incorporates the zero lower bound and the stock of public debt remains a promising topic for future research.

\section{Appendix: Derivation of Equilibrium Outcomes}

\subsection{Output and Inflation When the Zero Lower Bound Is Not Binding; Equations (7) and (8)}

Our goal here is to derive expressions for output and inflation as a function of the pre-determined inflation in period $t^{-1}$ and the model's "deep" parameters, when the zero lower bound on the nominal interest rate is not binding. 
Our first step is to use the Fisher equation (2) to replace the real interest rate in equation (1) by $r_{t}=i-\pi_{t}$. We get the expression for nominal interest rate from the Taylor rule in equation (5) and obtain the following relationship between $\pi_{t}$ and $Y_{t}$ :

$$
Y_{t}=\bar{Y}_{t}-\alpha\left(\Theta_{\pi}\left(\pi_{t}-\pi_{t}^{*}\right)+\Theta_{Y}\left(Y_{t}-\bar{Y} t\right)\right)+\varepsilon_{t}
$$

Next, we replace $\pi_{t}$ in the previous equation by using the Phillips curve (3):

$$
Y_{t}=\bar{Y}_{t}-\alpha\left(\Theta_{\pi}\left(\pi_{t-1}+\varphi\left(Y_{t}-\bar{Y}_{t}\right)+v_{t}-\pi_{t}^{*}\right)+\Theta_{Y}\left(Y_{t}-\bar{Y}_{t}\right)\right)+\varepsilon_{t}
$$

Note that, in the previous expression, output is the only endogenous variable at time $t$. As a result, we can solve for $Y_{t}$ as a function of the pre-determined inflation in period $t-1$ and the model parameters. After collecting the terms in $Y_{t}$, we obtain:

$$
Y_{t}=\bar{Y}_{t}+\frac{\alpha \Theta_{\pi}\left(\pi_{t}^{*}-\pi_{t-1}-v_{t}\right)+\varepsilon_{t}}{1+\alpha\left(\Theta_{\pi}{ }^{\varphi+\Theta} \Theta_{Y}\right)}
$$

which is equation (7).

Note that the output gap can be obtained from the previous expression:

$$
Y_{t}-\bar{Y}_{t}=\frac{\alpha \Theta_{\pi}\left(\pi_{t}^{*}-\pi_{t-1}-v_{t}\right)+\varepsilon_{t}}{1+\alpha\left(\Theta_{\pi}{ }^{\varphi+\Theta} \Theta_{Y}\right)}
$$

To obtain an expression for inflation in period $t$, we substitute the output gap into the Phillips curve (3) and use our assumption that agents have adaptive expectations. That is, $E_{t-1} \pi_{t}=\pi_{t-1}$. After collecting terms in $\pi_{t}$, we obtain the following expression for $\pi_{t}$ in terms of the parameters of the model and $\pi_{t-1}$ :

$$
\pi_{t}=\pi_{t-1}+\frac{\alpha \Theta^{\varphi\left(\pi_{t}^{*}-\pi_{t-1}-v_{t}\right)+\varphi \varepsilon_{t}} t}{1+\alpha\left(\Theta_{\pi}{ }^{\varphi+\Theta_{Y}}\right)}+v_{t}
$$

which, when rearranged, yields equation (8).

\subsection{Nominal Interest Rate When the Zero Lower Bound Is Not Binding-Equation (9)}

The equilibrium interest rate in (9) is obtained by substituting the expression for output gap and inflation into the Taylor rule. After some tedious algebra that involve collecting terms and rearranging, we obtain the following expression for interest rate:

$$
i=Q_{t}^{+} \frac{\left(1+\Theta_{\pi t}+\alpha \Theta_{Y t}\right)\left(\pi_{t-1}+v_{t}\right)-(1-\alpha \varphi) \Theta_{\pi t} \pi_{t}^{*}+\left(\Theta_{Y t}+\left(1+\Theta_{\pi t}\right) \varphi\right) \varepsilon_{t}}{1+\alpha \cdot\left(\Theta_{\pi t} \varphi^{++\Theta_{Y t}}\right)}
$$

which is equation (9).

To solve for the inflation threshold, set $i_{t}=0$ in the previous expression and solve for the value of $\pi_{t-1}$. After 
tedious rearranging of terms, we obtain:

$$
\pi_{t-1}^{c} \equiv \frac{(1-\alpha \varphi) \Theta_{\pi t} \pi_{t}^{*}-\left(1+\alpha \Theta_{\pi t} t^{\varphi+\alpha \Theta} \Theta_{Y t}\right) \varrho^{-}\left(\Theta_{\pi t} \varphi+\Theta_{Y t}+\varphi\right) \varepsilon_{t}}{1+\Theta_{\pi t}+\alpha \Theta_{Y t}}-v
$$

which is equation (11).

\subsection{Output and Inflation When the Zero Lower Bound Is Binding-Equations (14) and (15)}

Our goal here is to derive expressions for output and inflation as a function of the pre-determined inflation in period $t-1$ and the model's parameters, when the zero lower bound on the nominal interest rate is binding.

As before, our first step is to use the Fisher equation (2) to replace the real interest rate in equation (1) by $r_{t}=i-\pi_{t}$. However, since $i_{t}=0$, aggregate demand when the zero lower bound is binding is given by:

$$
Y_{t}=\bar{Y}_{t}+\alpha\left(\pi_{t}+\varrho\right)+\varepsilon
$$

Next, we replace $\pi_{t}$ in the previous equation by using the Phillips curve (3):

$$
Y_{t}=\bar{Y}_{t}-\alpha\left(\pi_{t-1}+\varphi\left(Y_{t}-\bar{Y}\right)_{t}+v_{t}+\varrho\right)+\varepsilon_{t}
$$

We solve for $Y_{t}$ as a function of the pre-determined inflation level $\pi_{t-1}$ and the model parameters:

$$
Y_{t}=\bar{Y}_{t}+\frac{\alpha\left(\pi_{t-1}+v_{t}+\varrho\right)+\varepsilon}{1-\alpha \varphi}
$$

which is equation (14).

Note that the output gap can be obtained from the previous expression:

$$
\mathrm{Y}_{\mathrm{t}}-\overline{\mathrm{Y}}_{\mathrm{t}}=\frac{\alpha\left(\pi_{\mathrm{t}-1}+v_{\mathrm{t}}+\mathrm{Q}\right)+\varepsilon_{\mathrm{t}}}{1-\alpha \varphi}
$$

To obtain an expression for inflation in period $t$, we substitute the output gap into the Phillips curve (3) and use our assumption that agents have adaptive expectations. That is, $E_{t-1} \pi_{t}=\pi_{t-1}$. After collecting terms in $\pi_{t}$, we obtain the following expression for $\pi_{t}$ in terms of the parameters of the model and $\pi_{t-1}$ :

After further simplification, we get

$$
\pi_{\mathrm{t}}=\pi_{\mathrm{t}-1}+\frac{\alpha \varphi\left(\pi_{\mathrm{t}-1}+v_{\mathrm{t}}+\varrho\right)+\varphi \varepsilon_{\mathrm{t}}}{1-\alpha \varphi}+v_{\mathrm{t}}
$$

$$
\pi_{t}=\frac{1}{1-\alpha \varphi}\left(\pi_{t-1}+v_{t}\right)+\frac{\varphi}{1-\alpha \varphi}(\alpha \varrho+\varepsilon)
$$

which is equation (15).

\section{References}

Atkeson, A., \& Kehoe, P. J. (2004). Deflation and depression: Is there an empirical link? The American Economic Review, 94(2), 99-103. http://dx.doi.org/10.1257/0002828041301588

Backus, D. K., \& Kehoe, P. J. (1992). International evidence on the historical properties of business cycles. The American Economic Review, 82(4), 864-888.

Benhabib, J., \& Spiegel, M. M. (2009). Moderate inflation and the deflation-depression link. Journal of Money, Credit and Banking, 41(4), 787-798. http://dx.doi.org/10.1111/j.1538-4616.2009.00232.x

Bernanke, B. S., \& Carey, K. (1996). Nominal wage stickiness and aggregate supply in the great depression. 
Quarterly Journal of Economics, 111(3), 853-83. http://dx.doi.org/10.2307/2946674

Carlin, W., \& Soskice, D. (2006). Macroeconomics: Imperfections, institutions, and policies. Oxford University Press.

Chari, V. V., Christiano, L. J., \& Kehoe, P. J. (1996). Optimality of the friedman rule in economies with distorting taxes. Journal of Monetary Economics, 37(2), 202-23. http://dx.doi.org/10.1016/0304-3932(96)01252-4

Cochrane, J. H. (2008). On the need for a new approach to analyzing monetary policy. NBER Macroeconomics Annual, 23, 427-448. http://dx.doi.org/10.1086/593092

Cole, H. L., \& Kocherlakota, N. (1998). Zero nominal interest rates: Why they are good and how to get them? Federal Reserve Bank of Minneapolis Quarterly Review, 22(2), 2-10.

Eggertsson, G. B,. \& Woodford, M. (2004). Policy options in a liquidity trap. The American Economic Review, 94(2), 76-79. http://dx.doi.org/10.1257/0002828041301740

Eggertsson, G. B., \& Woodford, M. (2003). The zero bound on interest rates and optimal monetary policy. Brookings Papers on Economic Activity, 1, 212-219.

Eichengreen, B., \& Jeffrey, S. J. (1985). Exchange rates and economic recovery in the 1930s. Journal of Economic History, 4(45), 925-46. http://dx.doi.org/10.1017/S0022050700035178

Friedman, M. (1969). The optimum quantity of money. Chicago: Aldine.

Ireland, P. N. (1996). The role of countercyclical monetary policy. The Journal of Political Economy, 104(4), 704-723. http://dx.doi.org/10.1086/262039

Jones, C. I. (2011). Macroeconomics (2nd ed.).

Krugman, P. (1998). Its baack! Japan's slump and the return of the liquidity trap. Brookings Papers on Economic Activity, 29(2), 137-187. http://dx.doi.org/10.2307/2534694

Lagos, R. (2010). Some results on the optimality and implementation of the Friedman rule in the search theory of money. Journal of Economic Theory, 145(4), 1508-1524. http://dx.doi.org/10.1016/j.jet.2009.05.010

Mankiw, G. N. (2010). Macroeconomics worth (7th ed.).

Rolnick, A. J., \& Weber, W. E. (1997). Money, inflation, and output under fiat and commodity standards. Journal of Political Economy, 105(6), 1308-1321. http://dx.doi.org/10.1086/516394

Taylor, J. B. (1993). Discretion versus policy rules in practice. Carnegie-Rochester Conference Series on Public Policy, 39, 195-214. http://dx.doi.org/10.1016/0167-2231(93)90009-L

\section{Copyrights}

Copyright for this article is retained by the author(s), with first publication rights granted to the journal.

This is an open-access article distributed under the terms and conditions of the Creative Commons Attribution license (http://creativecommons.org/licenses/by/3.0/). 